\title{
What causes human cancer? Approaches from the chemistry of DNA damage
}

\author{
Hiroshi Kasai
}

\begin{abstract}
To prevent human cancers, environmental mutagens must be identified. A common mechanism of carcinogenesis is DNA damage, and thus it is quite possible that environmental mutagens can be trapped as adducts by DNA components. It is also important to identify new types of DNA damaging reactions and clarify their mechanisms. In this paper, I will provide typical examples of our efforts to identify DNA damage by environmental agents, from chemistry-based studies. 1) Oxidative DNA damage: 8-Hydroxydeoxyguanosine (8-OHdG, 8-oxodG) was discovered during a structural study of DNA modifications caused in vitro by heating glucose, which was used as a model of cooked foods. We found that various oxygen radical-forming agents induced the formation of 8-OHdG in DNA, in vitro and in vivo. Analyses of the urinary $8-\mathrm{OHdG}$ levels are useful to assess the extent of oxidative DNA damage in a human population. 2) Lipid peroxide-derived DNA adducts: We searched for mutagens that react with deoxynucleosides, in model systems of lipid peroxidation. The reaction mixtures were analyzed by high performance liquid chromatography (HPLC), and we discovered various lipid peroxide-derived mutagens, including new mutagens. Some of these adducts were detected in human DNA. These mutagens may be involved in lipid peroxide-related cancers. 3) Methylation of cytosine by free radicals: Methylation of the cytosine C-5 position is an important mechanism of carcinogenesis, in addition to gene mutations. However, the actual mechanisms of de novo methylation in relation to environmental agents are not clear. We found that cytosine C-5 methylation occurred by a free radical mechanism. The possible role of this radical-induced DNA methylation in carcinogenesis will be discussed, in relation to the presently accepted concept of cancer epigenetics. In these studies, chemical analyses of the adducts formed in model reactions led to the discoveries of new mutagens and important types of DNA modifications, which seem to be involved in human carcinogenesis.
\end{abstract}

\section{Background}

In my early research as a graduate student (1969-1974) and a post-doctoral fellow (1975-1977) in natural product chemistry laboratories, I was involved in the determination of the structures of small amounts of naturally occurring modified nucleosides in transfer RNA (tRNA) and carcinogen-bound nucleosides. Among the modified nucleosides, an interesting discovery, published as my first research paper, was the fluorescent, methylated $1, \mathrm{~N}^{2}$-etheno-guanine-derivatized Yt base (wyosine nucleoside) in T. utilis tRNA ${ }^{\text {phe }}[1,2]$ (Fig. 1), which is biosynthesized from 3-methylguanine. I was intrigued by a previous report, in which an ethenoguanine derivative was formed in DNA by the reaction of deoxyguanosine (dGuo)

\footnotetext{
Correspondence: h-kasai@med.uoeh-u.ac.jp
}

Department of Environmental Oncology, Institute of Industrial Ecological Sciences, University of Occupational and Environmental Health, 1-1, Iseigaoka, Kitakyushu, Yahatanishi-ku 807-8555, Japan residues with the carcinogen glycidaldehyde [3, 4]. In tRNA, etheno-G stabilizes the tertiary structure of the anticodon-loop by stacking interactions with neighboring bases, leading to correct codon-anticodon interactions [5]. However, the etheno-G formed in DNA induces mutations by disturbing the DNA structure by stacking with neighboring bases, and by blocking normal G-C base-pairing by the $1, \mathrm{~N}^{2}$-etheno-modification [6]. After the study on the Yt base (wyosine nucleoside), my interest shifted to the modifications of nucleic acids by carcinogens. The Yt base actually "foreshadowed" the etheno-dG adducts formed by the hemin- $\omega$-3-fat-peroxidation system, encountered in the latter part of my research period (2006).

As a postdoctoral fellow, I was involved in studies on modifications of nucleic acids by carcinogens, such as benzo[a]pyrene (BP) and 7,12-dimethylbenz[a]anthracene (DMBA), mostly in collaboration with a group at the Institute of Cancer Research, Columbia University 


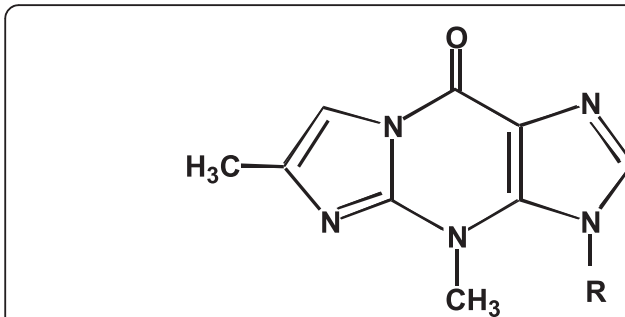

Fig. 1 Structure of wyosine

[7-12]. These studies involved the isolation of modified nucleosides (BP-Guo, DMBA-Guo) on a microgram scale and their structure determination by mass-, UV-, CD-, and NMR-spectra. These micro-techniques in organic chemistry actually formed the basis for my subsequent chemical studies on DNA adducts. These experiences also gave me hints toward the idea that environmental mutagens can be trapped as nucleosidemutagen-adducts.

On the occasion of the 10th anniversary of the foundation of the Journal, Genes and Environment, I am summarizing my 35 years of work on chemistry-based studies of DNA damage. This is also a review of my plenary lecture at ICEM Brazil in 2012, and my presentation at the Kitashi Mochizuki Memorial Symposium, Molecular Mechanisms of Mutagenesis, during the 2015 JEMS Meeting at Fukuoka, Japan.

\section{Introduction}

Based on epidemiological studies, diet and smoking are the main causes of human cancer [13]. To prevent cancer, it is important to identify unknown mutagens and carcinogens, especially in food, because in regard to smoking it is best to stop the habit, regardless of the mutagens in cigarette smoke. To isolate mutagens in food, the extraction, fractionation, and final purification are usually conducted based on the mutagenic activity, using bacterial mutagenicity tests such as the Ames test (Fig. 2-1). This method is especially useful for isolating stable frameshift-type mutagens, monitored by the Ames test with S9 mix. This test is generally used by many researchers to isolate mutagens. Using this method, I was involved in the isolation of the heterocyclic amine mutagen, 2-amino-3-methylimidazo[4,5-f]quinoline (IQ), from broiled sardines, in collaboration with Drs. T. Sugimura and M. Nagao of the National Cancer Center Research Institute, Tokyo $[14,15]$. However, the isolation of directly acting mutagens is difficult, because of their instability. A common mechanism of carcinogenesis is DNA damage [16], and many mutagens and carcinogens react with DNA, at the positions indicated by
1) Stable frameshift-type mutagens

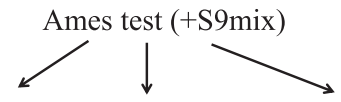

Food (model) $\rightarrow$ Extraction $\rightarrow$ Fractionation $\rightarrow$ Purification

$\rightarrow$ Structure determination of mutagens

2) Unstable direct-acting mutagens

Food (model) $\rightarrow$ Reaction with nucleosides

$\rightarrow$ Isolation of adducts $\rightarrow$ Purification

$\rightarrow$ Structure determination of adducts

$\rightarrow$ Presume mutagens $\rightarrow$ Chemical synthesis $\rightarrow$ Ames test

Fig. 2 Methods to identify mutagens

arrows (Fig. 3). Guanine (Gua) is the most reactive with mutagens. Thus, I thought it was quite possible that environmental mutagens, especially directly acting mutagens, could be trapped as Gua-adducts, and guanosine derivatives with a fluorescent group at the sugar moiety may be useful for mutagen-adduct analyses with high sensitivity, using HPLC coupled with a fluorescent detector (HPLC-Fl). For the structural characterization of adducts derived from unknown mutagens, certain amounts of the adducts (at least 300-500 micrograms) must be isolated for spectral measurements, such as mass-, UV-, and ${ }^{1} \mathrm{H}$ - and ${ }^{13} \mathrm{C}-\mathrm{NMR}$-spectra. Based on the determined structures of the adducts, the original mutagens can be presumed, and the mutagenicity can be confirmed using synthetic samples (Fig. 2-2).

In this paper, I discuss typical examples of our studies to identify DNA (nucleosides) damage induced by model systems, such as heated glucose, $\omega$-3-fat-hemin-, and $\omega$-6-fat hemin-peroxidation systems, especially in relation to diet. It is also important to identify new types of DNA damaging reactions and clarify their mechanisms. Accordingly, we examined the methylation of cytosine C- 5 by methyl radicals, generated from environmental and endogenous compounds. This may be related to epigenetic changes during carcinogenesis, in relation to inflammation.

\section{Sensitive detection of mutagens as adducts with a fluorescent guanosine derivative}

As sensitive methods for analyses of carcinogen-bound DNA adducts, the ${ }^{32} \mathrm{P}$-postlabeling and LC/MS/MS methods are widely used. However these methods are complicated ( ${ }^{32} \mathrm{P}$-postlabeling) or require expensive equipment (LC/MS/MS), and thus are not suitable for general adduct analyses. To detect mutagen-guanosine adducts with high sensitivity, the highly fluorescent guanosine derivative, 2'-deoxy-(2", 3"-dihydro-2", 4"- 


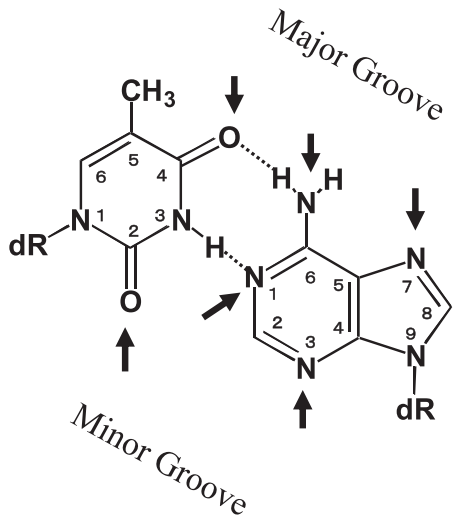

T-A pair

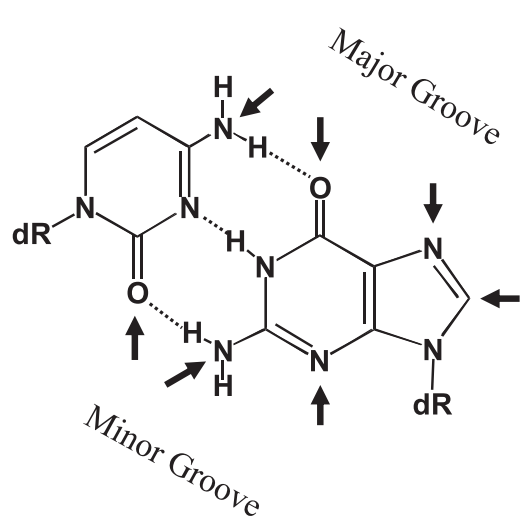

C-G pair

Fig. 3 Mutagen reactive sites (indicated by arrows) in DNA. In addition, mutagens react with the oxygen atoms of phosphodiester bonds

diphenyl-2"-hydroxy-3"-oxo-1"-pyrrolyl)guanosine (FG) (Fig. 4), was prepared [17]. As the base moiety of FG is the same Gua as in DNA, it is expected that mutagens will react with FG as well as DNA. In fact, after reactions of FG and known mutagens, such as glyoxal, methylglyoxal, 4-nitroquinoline $\mathrm{N}$-oxide (4NQO), and [2-(2-furyl)-3-(5-nitrofuryl)-acrylamide (AF-2) with or without S9mix, FG-mutagen-adducts were detected by HPLC-Fl analyses (Fig. 5). This method is also useful for the detection of adducts induced by unknown environmental mutagens in complex mixtures. For example, adduct formation by the reaction of FG and mutagenic heated glucose was revealed by the HPLC-Fl analysis method (Fig. 6) [18]. I hope that this method will be widely used in the future to test for adduct formation by various food extracts that may contain mutagens.

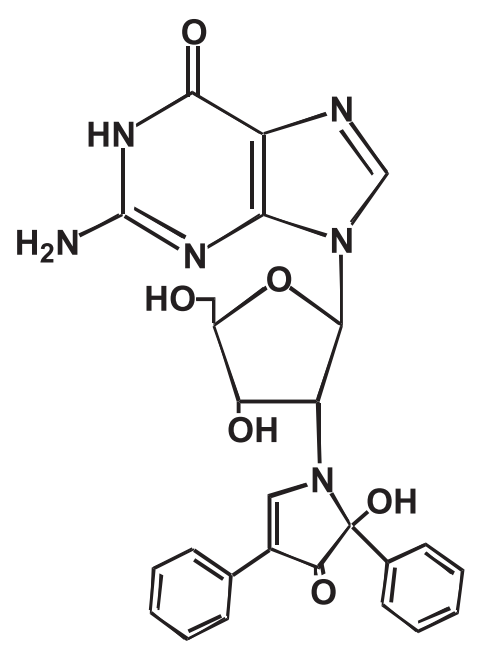

Fig. 4 Structure of the fluorescent guanosine derivative, FG

\section{Oxidative DNA damage: 8-Hydroxydeoxyguanosine}

When glucose is heated at $200{ }^{\circ} \mathrm{C}$ for 20 minutes, as a model reaction of cooking, it becomes mutagenic to $S$. typhimurium TA100 in the absence of S-9 mix. It was difficult to isolate the mutagens themselves, because they are unstable and some of them are volatile. Therefore, we analyzed the adducts formed after the reaction of heated glucose and a guanosine derivative, isopropylidene guanosine (ipGuo). The reason for the use of ipGuo, instead of Guo (guanosine) or dGuo, is that ipGuo adducts can be extracted with organic solvents such as ethyl acetate, while most of the unimportant water-soluble materials remained in the aqueous reaction mixture, and thus the adducts can be efficiently analyzed by HPLC after the extraction. To detect mutagen-ipGuo adducts, it is important to compare the HPLC profiles of the heated glucose-ipGuo reaction mixture (Fig. 7), the control of heated glucose only, and the control of ipGuo only. Only the peaks in the HPLC(reaction mixture), which are absent in the HPLC-(controls), are the real adducts formed between mutagens and ipGuo. We found two adducts, a glyoxal-ipGuo adduct and 8-OH-ipGuo. The latter adduct, 8-OH-ipGuo, was a new type of modification at that time, and thus we studied the mechanism of its formation.

Soon after the detection of the 8-OH-modification of ipGuo, we found that the $\mathrm{dG} \rightarrow 8$-OHdG modification is induced in the nucleoside and DNA by reactive oxygen species (ROS), such as hydroxyl radicals $(\bullet \mathrm{OH})$ (Fig. 8) $[19,20]$. Asbestos, UVB, diesel exhaust particles, and ionizing radiation, etc. induced 8-OHdG in DNA via ROS production [21]. Actually, heated starch (polymer of glucose) contained two ROS-forming mutagens, methylreductic acid (MRA) and hydroxymethylreductic acid (HMRA), which are five-membered ring compounds 

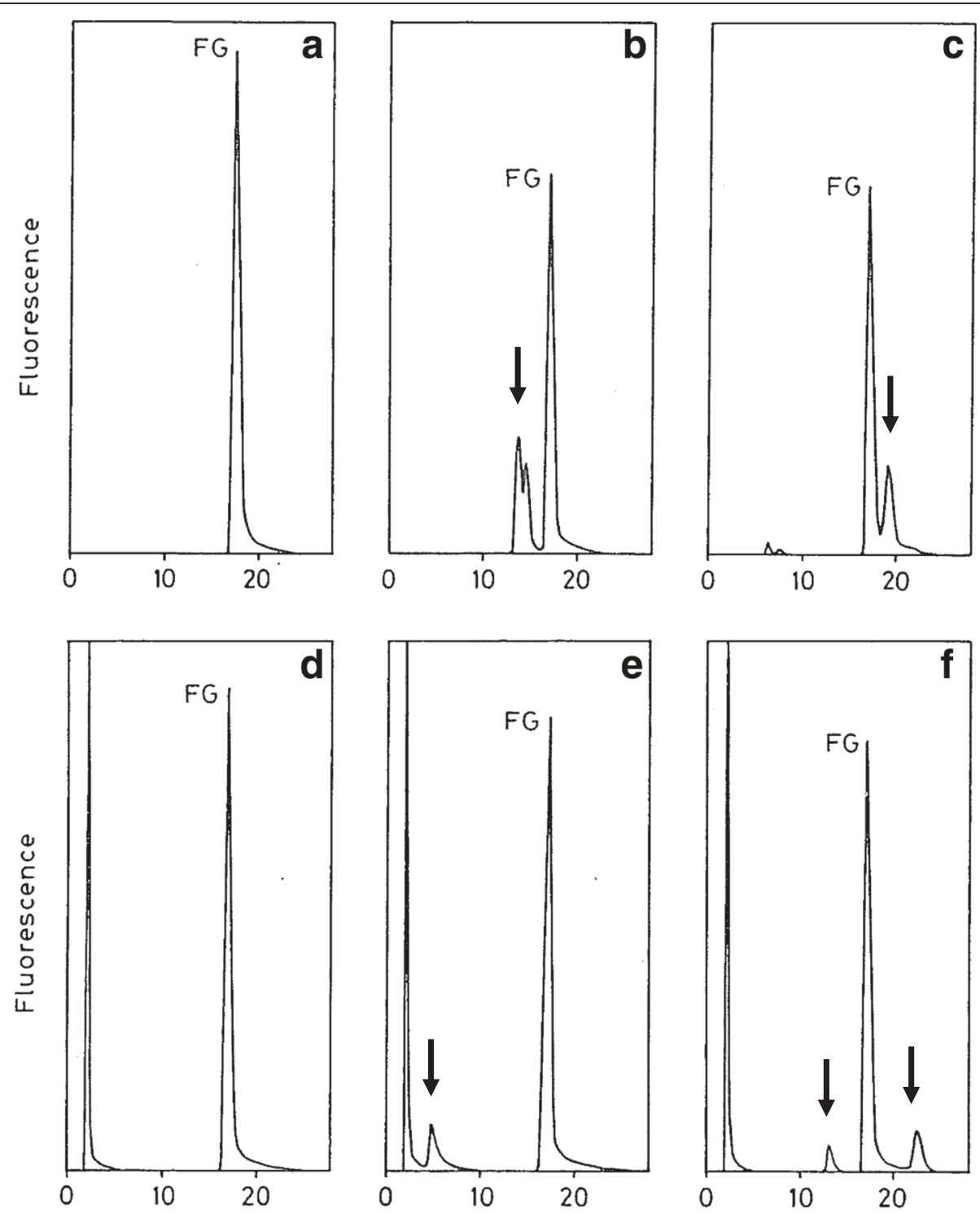

Retention Time ( $\mathrm{min}$ )

Fig. 5 Analysis of standard mutagen-FG adducts by HPLC-FI. a control FG, (b) glyoxal +FG, (c) methylglyoxal + FG, (d) control FG + S9 mix, (e) $4 \mathrm{NQO}+\mathrm{FG}+\mathrm{S} 9$ mix, (f) AF-2 + FG + S9 mix. Adduct peaks are indicated by arrows

[22]. Considerable amounts of these compounds were detected in various heat-processed foods, in the range of $17-$ $904 \mathrm{microgram} / \mathrm{g}$ food. In addition to ROS, 8-OHdG was also produced by other mechanisms, such as the hydration of 7-aryl-dGuo [23], the hydration of a guanine radical cation [24], long-range electron transfer [25], etc.

Since the discovery of $8-\mathrm{OHdG}$ formation in DNA, world-wide studies have been conducted on this modification from various aspects, such as mutation, repair and the mechanisms of its formation (Fig. 9). The biological significance of 8-OHdG was especially recognized after the detection of its mutagenic effects and the presence of its repair enzymes in mammalian cells [26]. It mispairs with A and induces the $\mathrm{GC} \rightarrow$ TA transversion mutation [27]. Based on their homology to the E. coli mutator genes, MutM, MutY, and MutT, the 8-OHdG related repair enzymes OGG1, MYH, and MTH1 were identified in mammalian cells [28, 29], which led to studies on the knock-out mouse and genetic polymorphisms in the human population. After Floyd et al. reported that $8-\mathrm{OHdG}$ can be detected with high sensitivity by an electrochemical detector (ECD) coupled to an HPLC [30], it was widely analyzed as a biomarker of oxidative stress, including studies on risk assessments of chemicals, effects of antioxidants, relationships to various ROS-related diseases, and aging. 


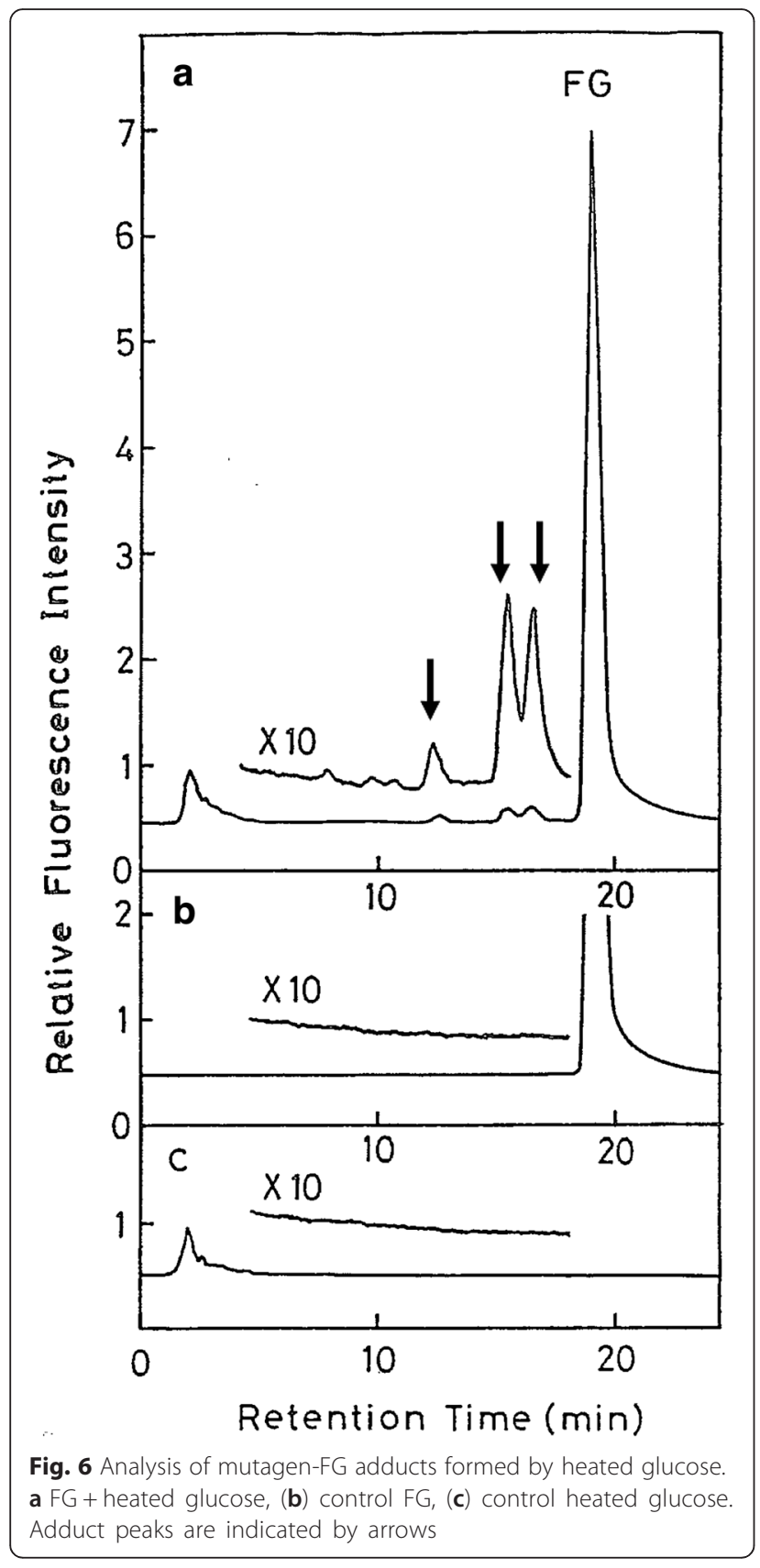

Over the past two decades, we have made efforts to establish an accurate method to measure 8-OHdG in cellular DNA and urine, as a biomarker of cellular oxidative stress in animals and humans [21, 31, 32]. I developed a simple and accurate method for urinary 8-OHdG analysis by HPLC-ECD [33], because the widely used ELISA method is inaccurate, due to the cross-reaction of the antibody with urea, a major urinary component [34]. The possible sources of urinary 8-OHdG may be the hydrolysis of 8-OHdGTP by the sanitization enzyme MTH1, nucleotide excision repair, or mismatch repair (Fig. 10) [32, 35]. The free base 8-hydroxyguanine (8-
OHGua) is also a good marker of oxidative stress [36, 37]. For the analysis of urinary 8-OHGua, the diet must be carefully controlled. For instance, the standard rodent diet CE-2 (CLEA) in animal experiments and fish consumption in human studies should be avoided [38], because these food sources contain large amounts of 8OHGua, and $90 \%$ of it is excreted into the urine within one week [31]. For animal experiments, we use a diet containing egg white as the protein source, which contains 50-fold less 8-OHGua as compared to CE-2. As sources of urinary 8-OHGua, base excision repair from oxidized DNA and the oxidation of Gua released by the hydrolytic degradation of DNA, RNA and nucleotides are possible [32].

The number of published reports with 8-OHdG in the title is presently 1,420 , and most have focused on human urine. The reports include the effects of chemicals (animal, 70; human, 120), radiation (84), diseases (494), lifestyles (694) and antioxidants (229). For example, in relation to dietary habits, when a vitamin-deficient diet (for two months) and a commercially available sweet beverage (for two weeks) were administered to mice, the urinary 8-OHdG levels clearly increased [39]. These results indicated that oxidative stress could be elevated by the prolonged intake of an unbalanced diet. Regarding the risk of ionizing radiation, the relationship between low dose $(<100 \mathrm{mSv})$ radiation and cancer risk is still unclear. We studied the effects of low dose radiation on 8-OHdG formation in mouse DNA and urine [40]. After whole body irradiation by X-rays, the $8-\mathrm{OHdG}$ levels in liver DNA and urine increased from the 500 and $200 \mathrm{mGy}$ doses, respectively. These results indicated that living organisms have a defense system against ionizing radiation, and a threshold seems to exist for oxidative DNA damage. Regarding human occupational and environmental exposure to chemicals, increases of $8-\mathrm{OHdG}$ were detected in relation to exposure to benzene, ethylbenzene, styrene, trichloroethylene, polycyclic aromatic hydrocarbons, di-(2-ethylhexyl)phthalate (plastic recycling), PCBs, dioxin, As, Cr, Cd, Ni, Se, nanoparticles (copier), PM2.5 in diesel exhaust particles, and environmental tobacco smoke. In addition, elevated 8-OHdG levels were detected in workers in the asbestos-, azodye-, and rubber-industries, coke oven workers, foundry workers, bus drivers, traffic policemen, hair salon employees (volatile organic compounds), people exposed to cooking oil fumes, ash treatment, and an antineoplastic drug (5-FU), and agricultural workers (organophosphate). For more information, please see the review papers $[21,41,42]$.

\section{Lipid peroxide-derived DNA adducts}

A high fat diet is a risk factor for various cancers, such as breast and prostate cancer $[43,44]$, and an elevated 


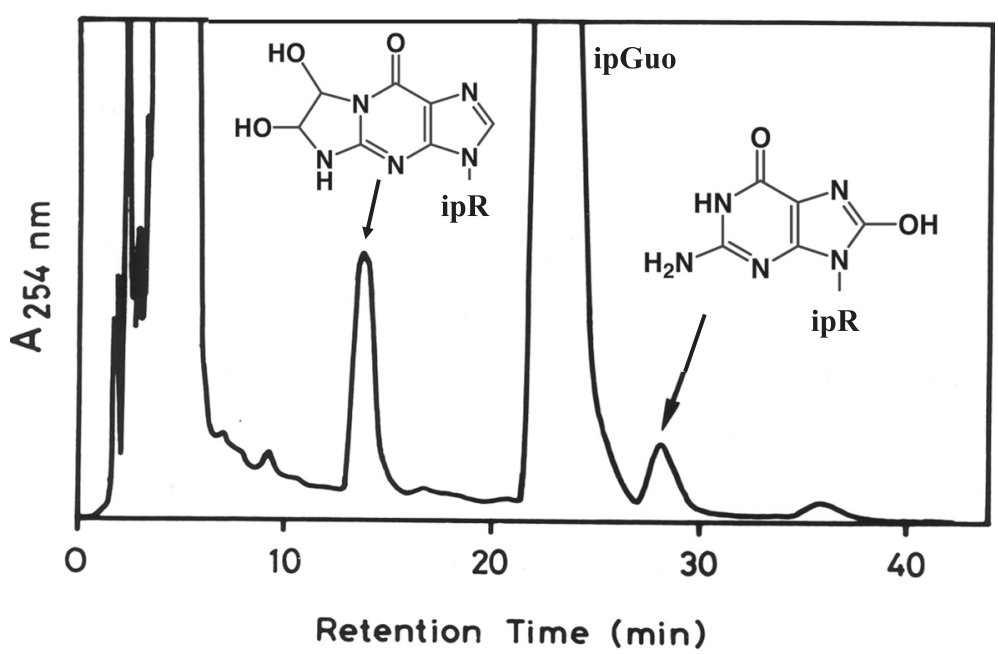

Fig. 7 Identification of isopropylidene guanosine (ipGuo) adducts formed by mutagenic heated glucose

risk of colon cancer is associated with red meat consumption [45]. Based on epidemiological studies, a higher intake of heme iron is positively associated with colorectal cancer risk [46]. The simultaneous feeding of a high fat diet and heme iron significantly increased the incidence of colon cancer in rats [47]. Therefore, it is interesting to study adduct formation by a lipid peroxidation model system, containing unsaturated fatty acid and hemin. First, I will mention the results of $\omega$-3-fat peroxidation. When dGuo was reacted with a model system of an emulsion of linoleic acid plus hemin, 6 adduct peaks were detected by HPLC. The structures of the possible mutagens involved in the adduct formation are shown in Fig. 11 [48]. Adduct 1 is produced by glyoxal, adduct 2 is produced by glyoxylic acid, adduct 3, 8-OHdG, is produced by ROS, and adducts 4 and 5 are produced by ethyl glyoxal. Adduct 6 showed a unique UV-spectrum. I noticed that it is very similar to that of wyosine, described in the Preface. It showed strong fluorescence on a TLC plate, similar to wyosine. The structure was determined to be $1, \mathrm{~N}^{2}$-etheno-dGuo with a 2-oxobutyl side chain (structure 6). It was proposed to be formed by the reaction of 4-oxo-2-hexenal (4-OHE) and dGuo. The synthetic 4OHE showed mutagenic activity in the TA100 and TA104

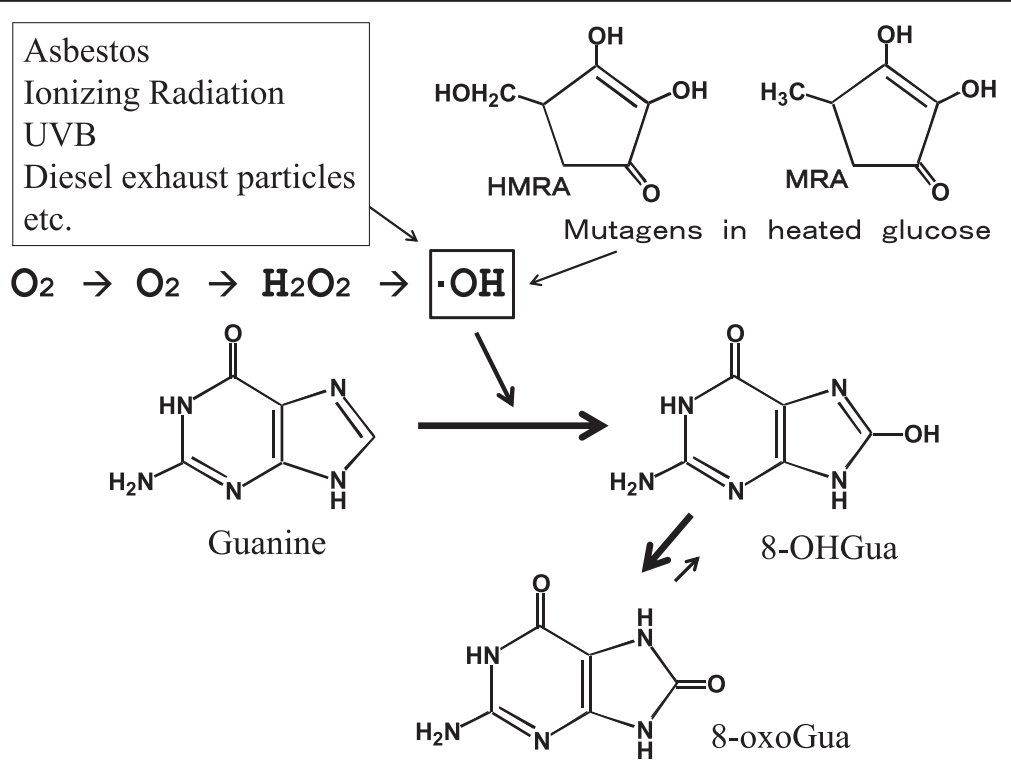

Fig. 8 Formation of 8-OHGua by ROS 


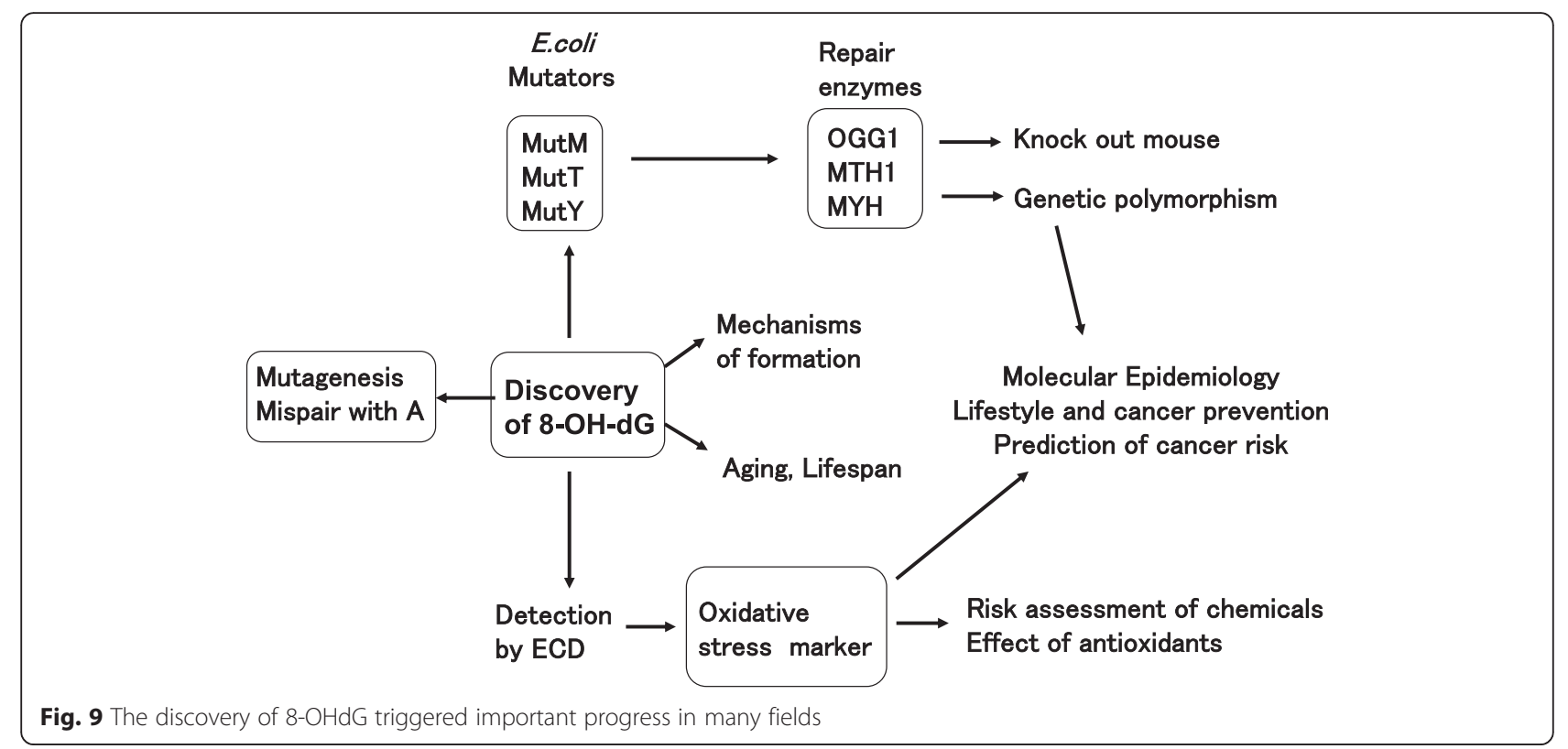

strains without $\mathrm{S} 9$ mix. Among these possible mutagens, 4-OHE and ethyl glyoxal have not been reported thus far. In addition to dGuo, 4-OHE also reacts with dCyd (deoxycytidine), $\mathrm{m}^{5} \mathrm{dCyd}$ (5-methyldeoxycytidine) and dAdo (deoxyadenosine) to give etheno-type adducts, in vitro. After the oral administration of 4-OHE to mice, these adducts were found in the mouse stomach, as detected by the LC/MS/MS method [49]. The detection range was 1-2 adducts per $10^{5}$ nucleosides. These adducts were also detected in human tissues, including the stomach, by the LC/MS/MS method, as reported by Matsuda and his collaborators [50]. We also determined the

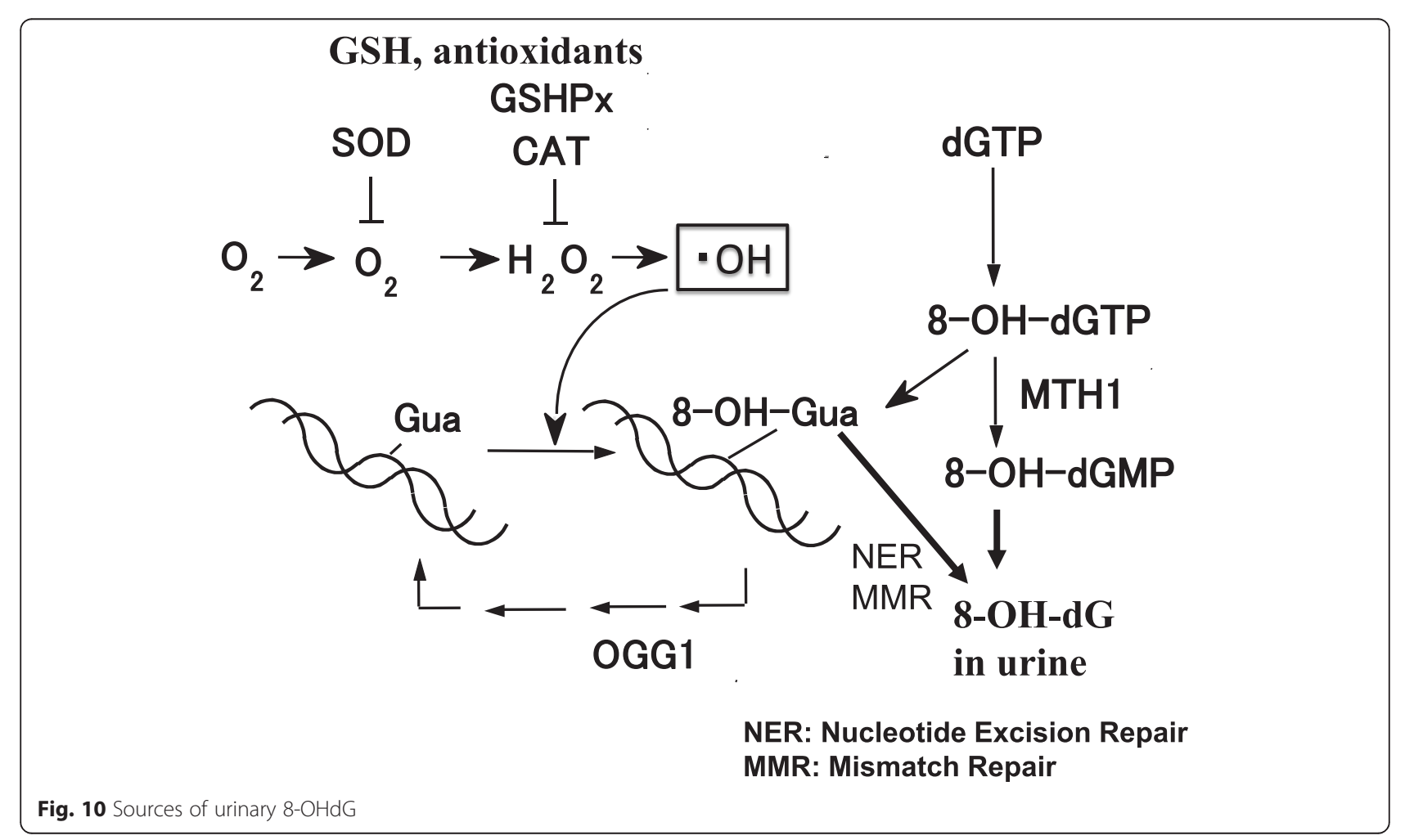




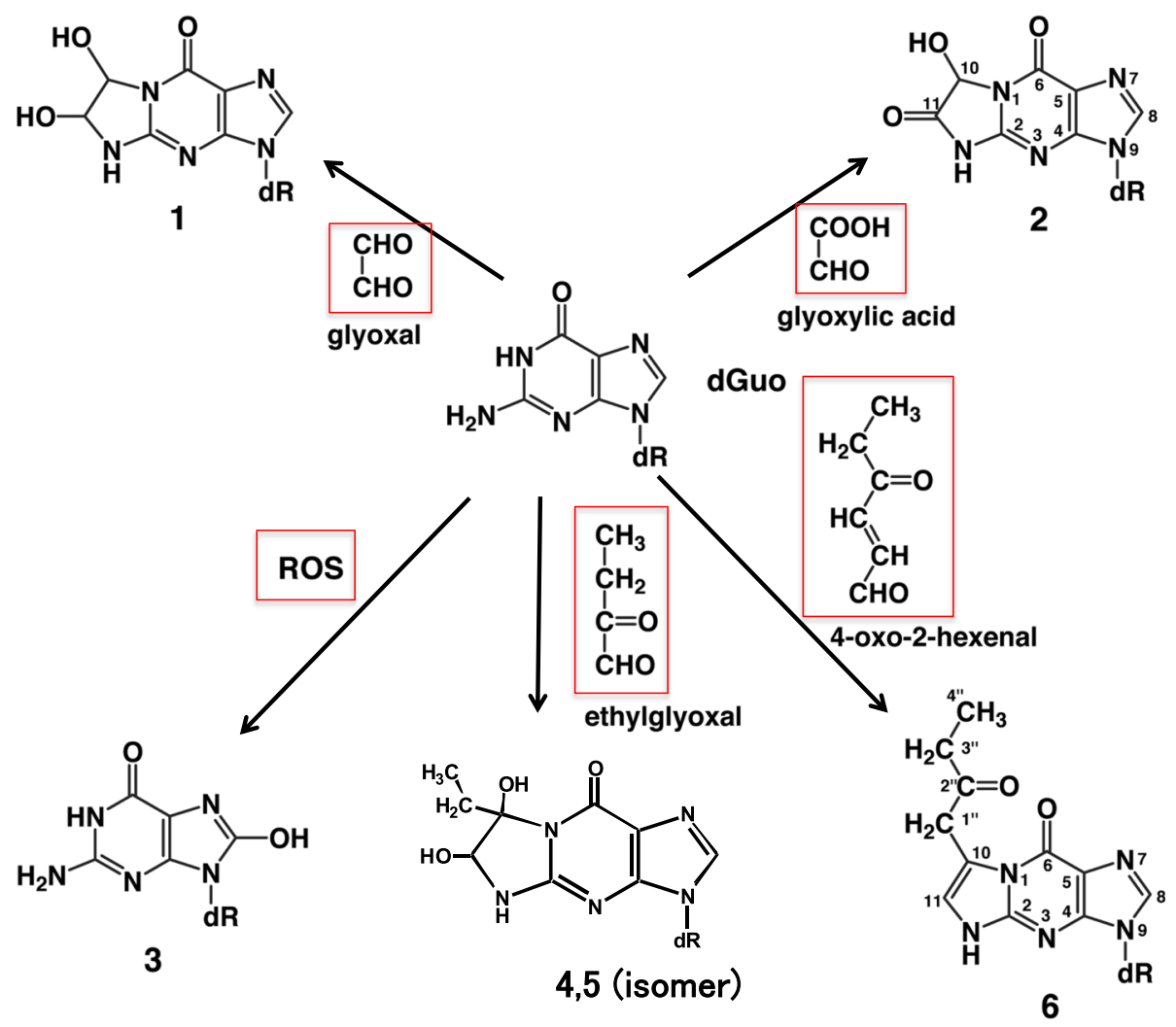

Fig. 11 Adduct formation of dGuo in an $\omega$-3-fat-hemin peroxidation model system. Mutagens involved in the adduct formation are shown in the red boxes

amounts of 4-OHE in cooked foods [51]. Considerably large amounts of 4-OHE were detected in cooking oil and broiled fish, in the range of 10 micrograms per $\mathrm{g}$ food.

Next, we examined adduct formation between nucleosides and an $\omega-6$ fat peroxidation model system [52]. Based on the literature, $\omega-6$ fat, rather than $\omega$-3-fat, and red meat seem to be more important risk factors in relation to colon cancer [53]. For this purpose, a model system, hemin plus ethyl linoleate, was reacted with deoxynucleosides in an emulsion, and the reaction products were analyzed by HPLC. As a result, etheno-type adducts were detected in the reaction mixtures with dAdo (Fig. 12, structures 7 and 8) and dCyd (Fig. 13, structures 9, 10, and 11). With dGuo, the adduct yield was low.

The mutagen involved in the formation of adducts 8 and 11 seemed to be 2,3-epoxyoctanal. In fact, synthetic 2,3-epoxyoctanal showed potent mutagenicity in the TA 100 and TA104 strains without S-9 mix. As many epoxy compounds are carcinogenic, it is quite possible that this compound may be involved in human carcinogenesis. It can be formed by various pathways; for example, from 9-hydroperoxy-octadecadienoic acid via 2,4-decadienal and 2-octenal, or from 13-hydroperoxy-octadecadienoic acid via an epoxy derivative. We found that 2,3- epoxyoctanal readily formed under acidic conditions. These results suggested that this mutagen could be efficiently formed during storage and cooking, or during digestion in the stomach, under acidic conditions.

A known mutagen, 4-oxo-2-nonenal (4-ONE), was presumed to be involved in the formation of adducts 7 and 9. In addition, 4-oxo-2-octenal (4-OOE) was proposed as the possible mutagen involved in the formation of the dCyd adduct 10 .

Notably, the adducts formed between nucleosides and lipid peroxide-derived mutagens (4-OHE, 4-ONE, 4OOE, 2,3-epoxyoctanal) were all detected in human tissue DNA [50, 54].

\section{Methylation of cytosine by free radicals}

In addition to genetic changes, epigenetic changes are an important mechanism of aberrant gene expression and carcinogenesis. Environmental factors and dietary and lifestyle factors are closely related to the induction of both genetic and epigenetic changes. A key molecule involved in epigenetic change is 5-methyl-2'-deoxycytidine $\left(\mathrm{m}^{5} \mathrm{dCyd}\right)$. Methylation of $\mathrm{CpG}$ islands is associated with gene silencing, while DNA hypermethylation of tumor suppressor genes plays a critical role in carcinogenesis [55]. It is widely accepted that the methyl group 


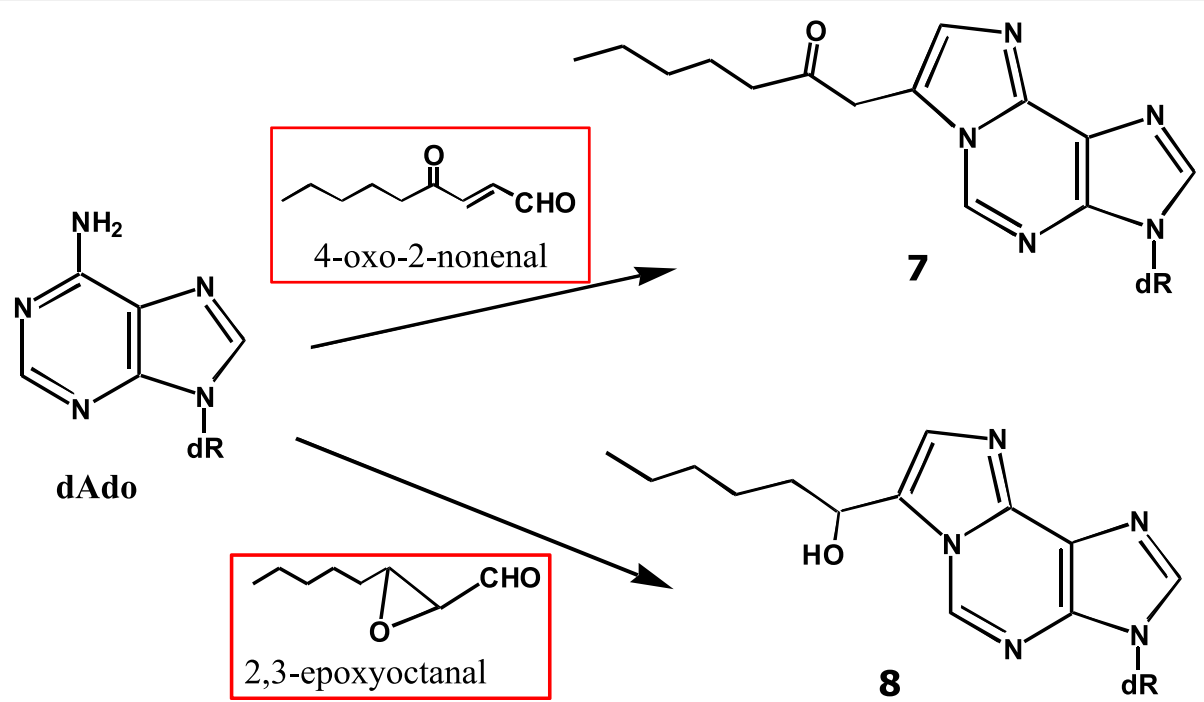

Fig. 12 Adduct formation of dAdo in an $\omega$-6-fat-hemin peroxidation model system. Mutagens involved in the adduct formation are shown in the red boxes

is enzymatically introduced at the $\mathrm{dCyd} \mathrm{C}-5$ position. DNA methyltransferases are involved in both de novo methylation and maintenance methylation [56]. After DNA methylation, methylated DNA binding domain protein (MBD) binds to the methylated site, a histone deacetylase is recruited, and finally gene inactivation occurs [57]. However, the exact mechanisms of hypermethylation, particularly in relation to environmental factors, are not clear.

It is interesting to propose a free radical mechanism for the formation of $\mathrm{m}^{5} \mathrm{dCyd}$, because the C-8methylation of dGuo by a methyl radical has been reported [58, 59]. In these studies, carcinogens, methyl hydrazine and dimethylhydrazine, and tumor promoters,

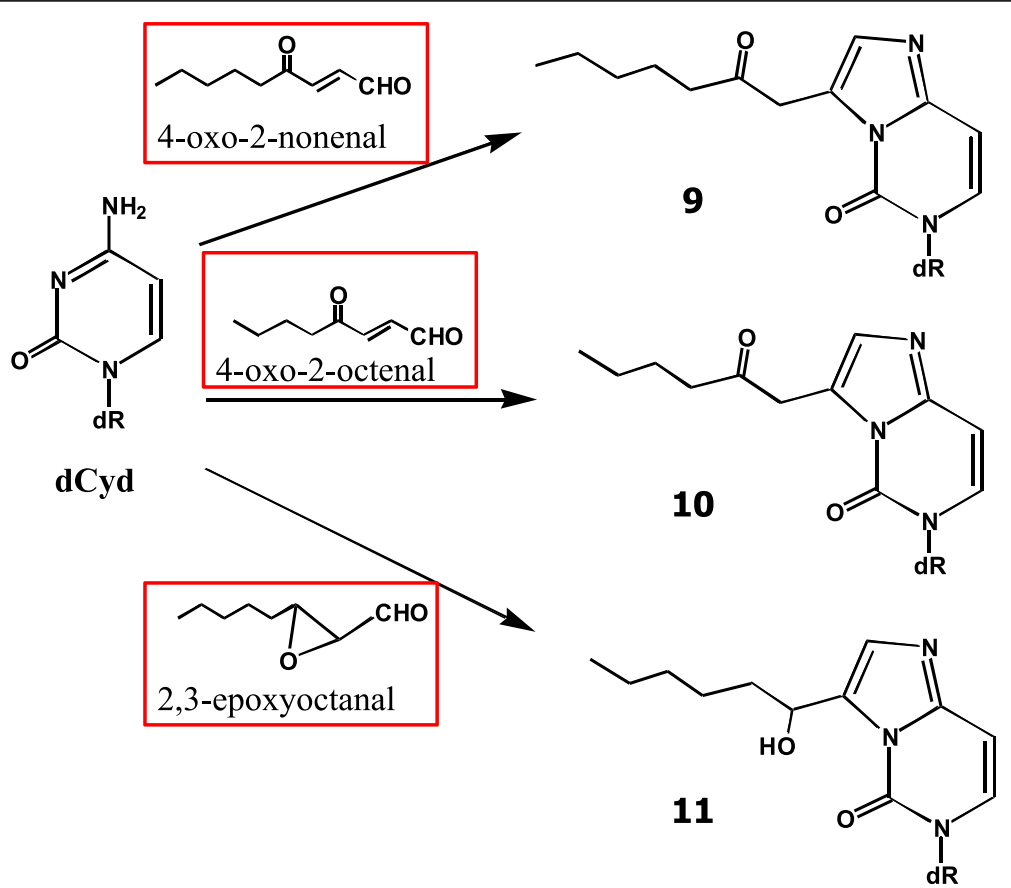

Fig. 13 Adduct formation of dCyd in an $\omega$-6-fat-hemin peroxidation model system. Mutagens involved in the adduct formation are shown in the red boxes 
$\mathrm{t}-\mathrm{Bu}-\mathrm{OOH}$ (t-butyl hydroperoxide) and cumene-OOH, were used to generate methyl radicals in the presence of Fe (iron). In our study, we tested the formation of $\mathrm{m}^{5} \mathrm{dCyd}$ from dCyd by $\mathrm{Bu}-\mathrm{OOH}$ and cumene-OOH. When $\mathrm{dCyd}$ and $\mathrm{Cu}-\mathrm{OOH}$ were reacted in the presence of ferrous ion, $\mathrm{m}^{5} \mathrm{dCyd}$ formation was clearly detected (Fig. 14) [60]. The retention time and the UV spectrum of the reaction product were the same as those of the standard $\mathrm{m}^{5} \mathrm{dCyd}$. The formation of $\mathrm{m}^{5} \mathrm{dCyd}$ was also confirmed by an immune-dot blot analysis. In these experiments, we demonstrated the formation of $\mathrm{m}^{5} \mathrm{dCyd}$ by methyl radicals, produced from the side chains of $\mathrm{t}$ $\mathrm{Bu}-\mathrm{OOH}$ and cumene-OOH. Cumen hydroperoxide and t-butyl hydroperoxide are environmental chemicals [61]. Large amounts of these chemicals are used as raw materials for the production of acetone and phenol, as intermediates for organic synthesis, and as catalysts for polymerization.

As another example, I will summarize our results about dCyd methylation by methionine sulfoxide (MetO) plus • OH [62]. Methionine sulfoxide is an oxidized product of methionine, and a biomarker of oxidative stress. It is generated in proteins by smoking [63], inflammation [64] and aging [65]. We confirmed that MetO generated methyl radicals with an oxygen radical forming system, and modified dCyd to $\mathrm{m}^{5} \mathrm{dCyd}$, in vitro (Fig. 14). To confirm whether this reaction is biologically relevant, MetO was administered to non-alcoholic steatohepatitis (NASH) mice [66]. It is well known that NASH mice have high oxidative stress in the liver. The incidences of hepatocellular carcinoma were higher in the MetO-administered groups. The multiplicity (number of tumors per mouse) was also increased in the MetO-administered groups. We also analyzed DNA methylation, by methylation-specific PCR. The DNA methylation status of the p16 gene promoter region was higher in the livers of the MetO-treated mice. These results suggested that MetO plus ROS actually triggers DNA methylation via methyl radicals in vivo.

A general scheme of methyl radical formation and dCyd methylation under oxidative stress conditions is shown in Fig. 15 [67, 68]. Endogenous compounds such as MetO, induced by smoking, inflammation and aging, can generate methyl radicals under oxidative stress conditions. Exogenous compounds, such as t-Bu-OOH, cumene- $\mathrm{OOH}$, dimethylhydrazine, and acetaldehyde, reportedly generate methyl radicals. It is possible that cytosine methylation occurs randomly in DNA. Clark and her collaborators proposed that a low level of seeding methylation occurs randomly at a very early stage of epigenetic change [69]. In the latter steps, sequence- and gene-specific DNA methylation occurs by MBD binding and the recruitment of DNMT (DNA methyltransferase), leading to a cancer-specific methylation pattern. We think our discovery of free radical-mediated cytosine methylation is related to this seeding methylation. Further studies are needed to assess the possibility of this radical DNA methylation mechanism in cellular DNA.

\section{Discussion}

About $90-95 \%$ of cancers are induced by environmental factors, including diet (30-35\%) and smoking (25$30 \%)$ [13]. Although the detailed mechanisms of carcinogenesis, such as gene mutations and epigenetic changes, are being clarified by recent progress in the molecular biology of cancer, the global identification of mutagens, especially in food, is necessary for cancer prevention. Only a limited number of food mutagens, such as aflatoxin B1, $\mathrm{N}$-nitrosamines, polycyclic aromatic hydrocarbons, heterocyclic amines, have been identified in foods [70]. I think they are only the tip of the iceberg, if we consider the thousands of unknown food mutagens.

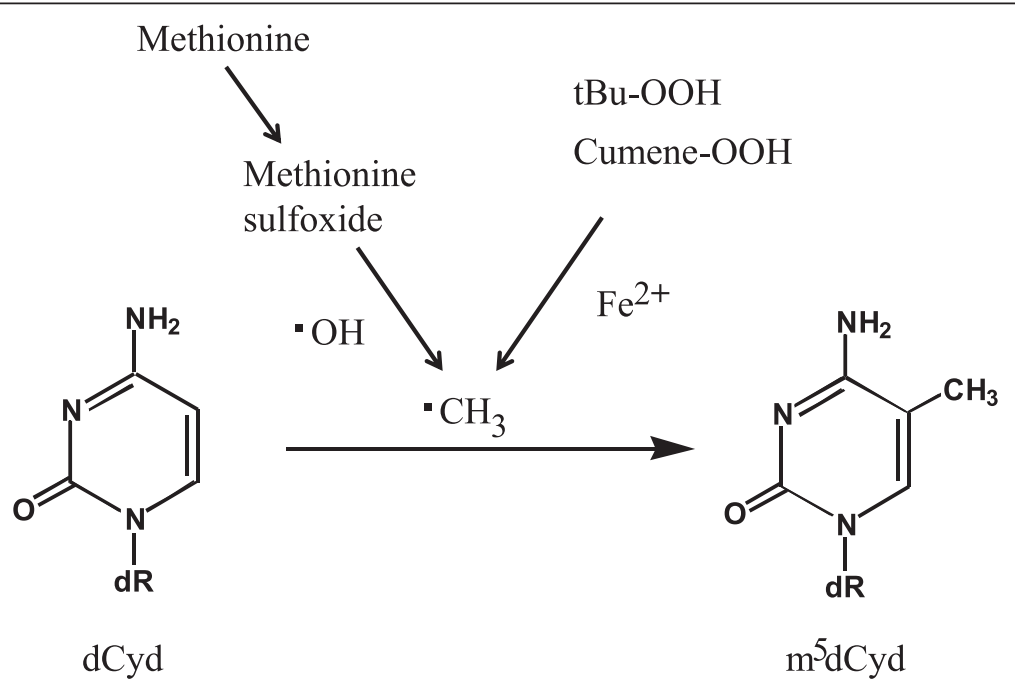

Fig. 14 Free radical-mediated dCyd C-5 methylation 


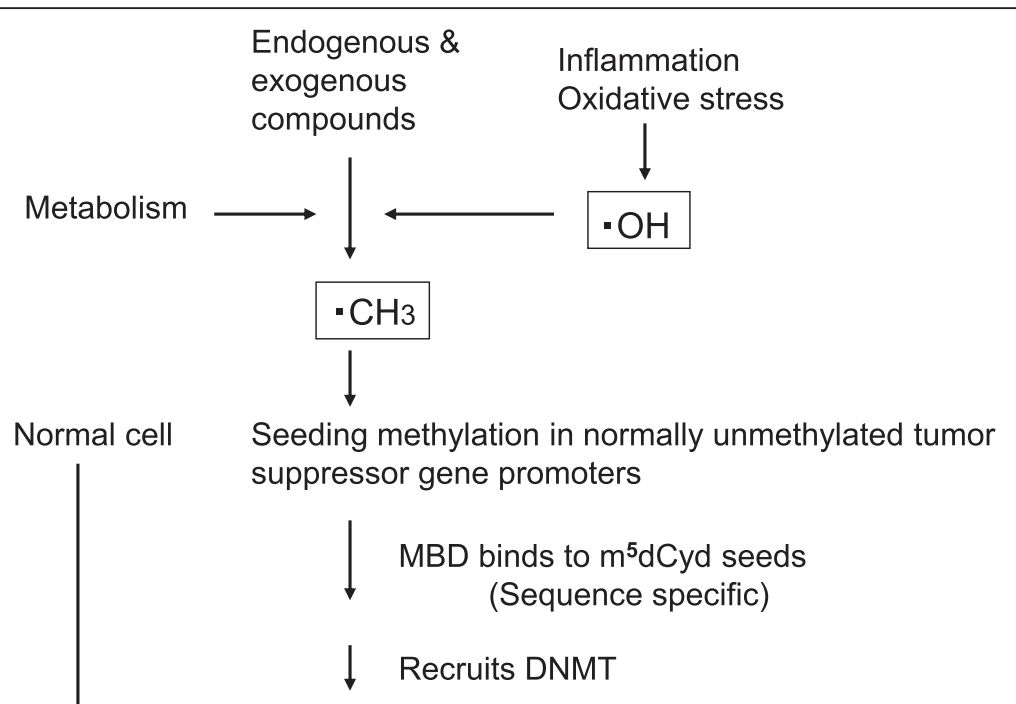

Methylation spread to adjacent regions

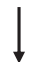

(Sequence specific)

Natural selection for growth advantage

Sequence specific \&

gene specific DNA hypermethylation

Fig. 15 Possible roles of free radicals in epigenetic changes during carcinogenesis

Methods such as ${ }^{32} \mathrm{P}$-postlabeling and LC/MS/MS can be used to detect many DNA adducts in human DNA with high sensitivity; however, the detected adducts are mostly unknown and none of the above known mutagens are the major sources of the adducts [71, 72]. We are currently only able to assess human cancer risk by using information such as the potency of genotoxicity, the amounts in foods, and the DNA adduct levels of these known mutagens. Without exhaustive research on food mutagens including unknown mutagens, risk assessments of food-derived cancer are either unreliable or impossible. To my great regret, fundamental studies to search for new environmental mutagens (not analyses of known mutagens), in food, air, and water, have seemed to decline recently. Young researchers are not interested in these projects, and have shifted their focus to molecular biology, because the former are high-risk; i.e., these projects require extensive efforts with the potential for meager outcomes. Looking back on my 35 years of research, fewer than 10 new discoveries of mutagens or DNA modifications were reported. They are the oxidative DNA damage 8-OHdG; the new mutagens MRA, HMRA, ethyl glyoxal, 4-oxo-2-hexenal, and 2,3-epoxyoctanal; and the methylation of cytosine $\mathrm{C}-5$ by a free radical mechanism, etc. These studies were neither efficient nor elegant, because the daily experiments were mostly fruitless and interesting results were only obtained on very rare occasions. Fortunately, most of the adducts detected by HPLC (7 out of 11) were new types of modifications, except for the adducts with ONE, glyoxal, and glyoxylic acid. Furthermore, many of the adducts were detected in human DNA by LC/MS/MS. Especially, 8OHdG was the seed for many important research developments in various fields, as shown in Fig. 9. In a sense, these unique chemistry-based approaches are more efficient for new discoveries, as compared to molecular biology-based approaches. In the latter approaches, many researchers must compete to obtain new findings with similar projects in the modern trend.

Further chemistry-based studies to search for new environmental mutagens and DNA modifications should be encouraged, especially for young researchers.

\section{Conclusion}

To prevent human cancers, environmental mutagens must be identified. Chemical analyses of the adducts formed in model reactions led to the discoveries of new mutagens and important types of DNA modifications, which seem to be involved in human carcinogenesis. 


\section{Acknowledgments}

I thank Dr. S. Nishimura, the previous head of the Biology Division, National Cancer Center Research Institute, Tokyo, Japan, for encouragement and support of my studies in the former period (1982-1993). I also thank all of my collaborators, especially Drs. T. Hirano, H. Kamiya, K. Kawai, Y.S. Li, and all of the graduated students, of the Department of Environmental Oncology, University of Environmental Health, Kitakyushu, Japan, for their support in the latter period (1994-present).

\section{Competing interests}

The author declares that he has no competing interests.

\section{Received: 8 April 2016 Accepted: 11 May 2016}

\section{Published online: 01 July 2016}

\section{References}

1. Kasai H, Goto M, Takemura S, Goto T, Matsuura S. Structure and synthesis of a fluorescent Y-like base from Torulopsis utilis tRNA. Tetrahedron Lett. 1971:9:2725-8

2. Kasai H, Goto M, Ikeda K, Zama M, Mizuno Y, Takemura S, Matsuura S, Sugimoto T, Goto T. Structure of wye (Yt base) and wyosine (Yt) from Torulopsis utilis phenylalanine transfer ribonucleic acid. Biochemistry. 1976; 15:898-904.

3. Goldschmidt BM, Blazej TP, Van Duuren BL. The reaction of guanosine and deoxyguanosine with glycidaldehyde. Tetrahedron Lett. 1968:13:1583-6.

4. Van Duuren BL, Loewengart G. Reaction of DNA with glycidaldehyde. Isolation and identification of a deoxyguanosine reaction product. J Biol Chem. 1977;252:5370-1.

5. Davanloo P, Sprinzl M, Cramer F. Proton nuclear magnetic resonance of minor nucleosides in yeast phenylalanine transfer ribonucleic acid. Conformational changes as a consequence of aminoacylation, removal of $Y$ base, and codon-anticodon interaction. Biochemistry. 1979:18:3189-99.

6. Zanya Z, Lukin M, Johnson F, De Los Santos C. Solution structure of duplex DNA containing the mutagenic lesion 1,N2-etheno-2'-deoxyguanine. Biochemistry. 2008;47:4606-13.

7. Weinstein IB, Jeffrey AM, Jennette KW, Blobstein SH, Harvey RG, Harris C, Autrup H, Kasai H, Nakanishi K. Benzo[a]pyrene diol epoxides as intermediates in nucleic acid binding in vitro and in vivo. Science. 1976;193:592-5.

8. Jeffrey AM, Blobstein SH, Weinstein IB, Beland FA, Harvey RG, Kasai H, Nakanishi K. Structure of 7,12-dimethylbenz[a]anthracene-guanosine adducts. Proc Natl Acad Sci U S A. 1976;73:2311-5.

9. Nakanishi K, Kasai H, Cho H, Harvey RG, Jeffrey AM, Jennette KW, Weinstein I. Absolute configuration of a ribonucleic acid adduct formed in vivo by metabolism of benzo[a]pyrene. J Am Chem Soc. 1977;99:258-60.

10. Kasai H, Nakanishi K, Frenkel K, Grunberger D. Structure of 7,12dimethylbenz[a]anthracene 5,6-epoxide derivative linked to the ribose moiety of quanosine. J Am Chem Soc. 1977:99:8500-2.

11. Kasai H, Nakanishi $\mathrm{K}$ and Traiman S. Two micromethods for determining the linkage of adducts formed between polyaromatic hydrocarbons and nucleic acid bases. J. Chem. Soc. Chem. Comm. 1978;1:798-800.

12. Frenkel K, Grunberger D, Kasai H, Komura H, Nakanishi K. Identification of novel 7,12-dimethylbenz[a]anthracene adducts in cellular ribonucleic acid. Biochemistry. 1981;20:4377-81.

13. Harvard Report on Cancer Prevention Vol.1: Causes of human cancer. Cancer Causes Control 1996; 7 Suppl 1:S3-59

14. Kasai H, Nishimura S, Nagao M, Takahashi Y, Sugimura T. Fractionation of a mutagenic principle from broiled fish by high-pressure liquid chromatography. Cancer Lett. 1979:7:343-8

15. Kasai H, Yamaizumi Z, Wakabayashi K, Nagao M, Sugimura T, Yokoyama S, Miyazawa T, Spingarn NE, Weisburger JH, Nishimura S. Potent novel mutagens produced by broiling fish under normal conditions. Proc Japan Acad. 1980;56B:278-83.

16. Singer B, Grunberger D. Molecular biology of mutagens and carcinogens. New York: Plenum Press; 1983.

17. Kasai H, Hayami H, Yamaizumi Z, Saito H, Nishimura S. Detection and identification of mutagens and carcinogens as their adducts with guanosine derivatives. Nucl Acids Res. 1984;12:2127-36.

18. Kasai $H$, Yamaizumi Z, Nishimura S. Detection and identification of mutagens by the adducts formed upon reaction with guanosine derivatives. IARC Sci Publ. 1986;70:413-8.
19. Kasai $\mathrm{H}$, Nishimura S. Hydroxylation of deoxyguanosine at $\mathrm{C}-8$ position by ascorbic acid and other reducing agents. Nucl Acids Res. 1984:12:2137-45.

20. Kasai $\mathrm{H}$, Nishimura $\mathrm{S}$. Hydroxylation of guanine in nucleosides and DNA at the $\mathrm{C}-8$ position by heated glucose and oxygen radical forming agents. Environ Health Perspect. 1986;67:111-6.

21. Kasai H. Analysis of a form of oxidative DNA damage, 8-hydroxy-2'deoxyguanosine, as a marker of cellular oxidative stress during carcinogenesis. Mutation Res. 1997;387:147-63.

22. Kasai H, Nakayama M, Toda N, Yamaizumi Z, Oikawa J, Nishimura S. Methylreductic acid and hydroxymethylreductic acid: oxygen radical forming agents in heated starch. Mutat Res. 1989;214:159-64.

23. Kohda K, Tada M, Hakura A, Kasai H, Kawazoe Y. Formation of 8hydroxyguanine residues in DNA treated with 4-hydroxyamino-quinoline 1oxide and its related compunds in the presence of seryl-AMP. Biochem Biophys Res Commun. 1987:149:1141-8.

24. Kasai H, Yamaizumi Z, Berger M, Cadet J. Photosensitized formation of 7,8dihydro-8-oxo-2'-deoxyguanosine (8-hydroxy-2'-deoxyguanosine) in DNA by riboflavin - A nonsinglet oxygen mediated reaction. J Am Chem Soc. 1992; 114:9692-4.

25. Nunez ME, Hall DB, Barton JK. Long-range oxidative damage to DNA: effects of distance and sequence. Chem Biol. 1999:6:85-97.

26. Kasai H, Nishimura S. Formation of 8-hydroxydeoxyguanosine in DNA by oxygen radicals and its biological significance. In: Sies $\mathrm{H}$ (ed) Oxidative stress: oxidants and antioxidants. London: Academic Press; 1991. pp 99-116.

27. Shibutani S, Takeshita M, Grollman AP. Insertion of specific bases during DNA-synthesis past the oxidation-damaged base 8-oxodG. Nature. 1991; 349:431-4.

28. Sekiguchi M, Tsuzuki T. Oxidative nucleotide damage: consequences and prevention. Oncogene. 2002;21:8895-904.

29. Nishimura S. Mammalian Ogg1/Mmh gene plays a major role in repair of the 8-hydroxyguanine lesion in DNA. Prog Nucleic Acid Res Mol Biol. 2001; 68:107-23.

30. Floyd RA, Watson JJ, Wong PK, Altmiller DH, Rickard RC. Hydroxyl free radical adduct of deoxyquanosine: sensitive detection and mechanisms of formation. Free Radic Res Commun 1986;1:163-72.

31. Kawai K, Li YS, Kasai H. Accurate measurement of 8-OH-dG and 8-OH-Gua in mouse DNA, urine and serum; Effect of X-irradiation. Genes and Environ. 2007:29:107-14.

32. Kasai H, Kawai K, Li Y-S. Analysis of 8-OH-dG and 8-OH-Gua as biomarkers of oxidative stress. Genes and Environ. 2008:30:33-40.

33. Kasai H. A new automated method to analyze urinary 8-hydroxydeoxyguanosine by a high-performance liquid chromatography-electrochemical detector system. J Radiat Res. 2003;44:185-9.

34. Song MF, Li YS, Ootsuyama Y, Kasai H, Kawai K, Ohta M, Eguchi Y, Yamato H, Matsumoto Y, Yoshida R, Ogawa Y. Urea, the most abundant component in urine, cross-reacts with a commercial 8-OH-dG ELISA kit and contributes to overestimation of urinary 8-OH-dG. Free Radic Biol Med. 2009:47:41-6.

35. Evans MD, Saparbaev M, Cooke MS. DNA repair and the origins of urinary oxidized 2'-deoxyribonucleosides. Mutagenesis. 2010;25:433-42.

36. Svoboda P, Maekawa M, Kawai K, Tominaga T, Savela K, Kasai H. Urinary 8hydroxyguanine may be a better marker of oxidative stress than 8hydroxydeoxyguanosine in relation to the life spans of various species. Antioxid Redox Signal. 2006;8:985-92.

37. Li YS, Song MF, Kasai H, Kawai K. 8-Hydroxyguanine in urine and serum as an oxidative stress marker: effects of diabetes and aging. J UOEH. 2013;35:119-27.

38. Kawai K, Svoboda P, Kasai H. Detection of genotoxic nucleosides, 8hydroxydeoxyguanosine, 8-hydroxyguanosine and free base 8hydroxyguanine in fish food products. Genes and Environ. 2006;28:120-2.

39. Li YS, Kawai K, Kasai H. Increase of urinary 8-OH-dG levels after administration of a vitamin-deficient diet and a sweet beverage. Genes and Environ. 2007;29:128-32.

40. Li YS, Song MF, Kasai H, Kawai K. Generation and threshold level of 8-OHdG as oxidative DNA damage elicited by low dose ionizing radiation. Genes Environ. 2013:35:88-92.

41. Loft S, Poulsen HE. Cancer risk and oxidative DNA damage in man. J Mol Med. 1996:74:297-312

42. Kasai H, Kawai K. 8-Hydroxyguanine, an oxidative DNA and RNA modification, Modified Nucleic Acids in Biology and Medicine, RNA Technologies, Springer International Publishing $A G$, in press 
43. Carroll KK, Braden LM. Dietary fat and mammary carcinogenesis. Nutr Cancer. 1984;6:254-9.

44. Gallagher RP, Kutynec CL. Diet, micronutrients and prostate cancer: a review of the evidence. Can J Urol. 1997;4:22-7.

45. Giovannucci E, Rimm EB, Stampfer MJ, Colditz GA, Ascherio A, Willett WC. Intake of fat, meat, and fiber in relation to risk of colon cancer in men. Cancer Res. 1994;54:2390-7.

46. Bastide NM, Pierre FH, Corpet DE. Heme iron from meat and risk of colorectal cancer: a meta-analysis and a review of the mechanisms involved. Cancer Prev Res. 2011:4:177-84.

47. Sawa T, Akaike T, Kida K, Fukushima Y, Takagi K, Maeda H. Lipid peroxyl radicals from oxidized oils and heme-iron: implication of a high-fat diet in colon carcinogenesis. Cancer Epidemiol Biomarkers Prev. 1998;7:1007-12.

48. Maekawa M, Kawai K, Takahashi Y, Nakamura H, Watanabe T, Sawa R, Hachisuka K, Kasai H. Identification of 4-oxo-2-hexenal and other direct mutagens formed in model lipid peroxidation reactions as dG-adducts. Chem Res Toxicol. 2006;19:130-8.

49. Kasai H, Maekawa MK, Kawai K, Hachisuka K, Takahashi Y, Nakamura H, Sawa R, Matsui S, Matsuda T. 4-Oxo-2-hexenal, a mutagen formed by $\omega-3$ fat peroxidation, causes DNA adduct formation in mouse organs. Ind Health. 2005;43:699-701.

50. Chou PH, Kageyama S, Matsuda S, Kanemoto K, Sasada Y, Oka M, Shinmura K, Mori H, Kawai K, Kasai H, Sugimura H, Matsuda T. Detection of lipid peroxidation-induced DNA adducts caused by 4-oxo-2(E)-nonenal and 4-oxo2(E)-hexenal in human autopsy tissues. Chem Res Toxicol. 2010;23:1442-8.

51. Kawai K, Matsuno K, Kasai H. Detection of 4-oxo-2-hexenal, a novel mutagenic product of lipid peroxidation, in human diet and cooking vapor. Mutat Res. 2006:603:186-92

52. Kawai K, Kawasaki Y, Kubota Y, Kimura T, Sawa R, Matsuda T, Kasai H. Identification of octenal-related $\mathrm{dA}$ and $\mathrm{dC}$ adducts formed by reactions with a hemin- $\omega-6$-fat peroxidation model system. Chem Res Toxicol. 2013; 26:1554-60.

53. Bartsch H, Nair J, Owen RW. Dietary polyunsaturated fatty acids and cancers of the breast and colorectum: emerging evidence for their role as risk modifiers. Carcinogenesis. 1999;20:2209-18.

54. Matsuda T, Matsuda Y, Kawai K, Kasai H, Sugimura H. Quantitation of 2octenal related DNA adducts in human tissues. Abstract (P-029). Okayama: The 42nd Annual Meeting of JEMS; 2013.

55. Nephew KP, Huang TH. Epigenetic gene silencing in cancer initiation and progression. Cancer Lett. 2003;190:125-33.

56. Benbrahim-Tallaa L, Waterland RA, Dill AL, Webber MM, Waalkes MP. Tumor suppressor gene inactivation during cadmium-induced malignant transformation of human prostate cells correlates with overexpression of de novo DNA methyltransferase. Environ Health Perspect. 2007;115:1454-9.

57. Clouaire T, de Las Heras Jl, Merusi C, Stancheva I. Recruitment of MBD1 to target genes requires sequence-specific interaction of the MBD domain with methylated DNA. Nucleic Acids Res. 2010;38:4620-34.

58. Maeda M, Nushi K, Kawazoe Y. Studies on chemical alterations of nucleic acids and their components. VII. C alkylation of purine bases through free radical process catalyzed by ferrous ion. Tetrahedron. 1974;30:2677-82.

59. Hix S, Morais Mda S, Augusto O. DNA methylation by tert-butyl hydroperoxide-iron (II). Free Radic Biol Med. 1995;19:293-301.

60. Kasai H, Kawai K. DNA methylation at the C -5 position of cytosine by methyl radicals: a possible role for epigenetic change during carcinogenesis by environmental agents. Chem Res Toxicol. 2009;22:984-9.

61. Murray AR, Kisin ER, Kommineni C, Vallyathan V, Castranova V, Shvedova AA Pro/antioxidant status and AP-1 transcription factor in mouse skin following topical exposure to cumene hydroperoxide. Carcinogenesis. 2007;28:1582-8.

62. Kawai K, Li YS, Song MF, Kasai H. DNA methylation by dimethyl sulfoxide and methionine sulfoxide triggered by hydroxyl radical and implications for epigenetic modifications. Bioorg Med Chem Lett. 2010;20:260-5.

63. Carp H, Miller F, Hoidal JR, Janoff A. Potential mechanism of emphysema: $a_{1}$-proteinase inhibitor recovered from lungs of cigarette smokers contains oxidized methionine and has decreased elastase inhibitory capacity. Proc Natl Acad Sci U S A. 1982;79:2041-5.

64. Hosako M, Ogino T, Omori M, Okada S. Cell cycle arrest by monochloramine through the oxidation of retionblastoma protein. Free Radic Biol Med. 2004; 36:112-22.

65. Onorato JM, Thorpe SR, Baynes JW. Immunohistochemical and ELISA assay for biomarkers of oxidative stress in aging and disease. Ann N Y Acad Sci. 1998;854:277-90.
66. Kawai K, Li YS, Song MF, Ootsuyama Y, Kakehashi A, Wanibuchi H, Ootsuyama A, Norimura T, Kasai H. Methionine sulfoxide stimulates hepatocarcinogenesis in non-alcoholic steatohepatitis (NASH) mouse: Possible role of free radical-mediated DNA methylation. Genes Environ. 2012;34:123-8.

67. Kasai H, Kawai K, Li YS. DNA methylation at the C-5 position of cytosine by a methyl radical: A link between environmental agents and epigenetic change. Genes Environm. 2011;33:61-5.

68. Kasai H, Kawai K, Li YS. Free radical-mediated cytosine C-5 methylation triggers epigenetic changes during carcinogenesis. Biomol Concepts. 2013;4:213-20.

69. Stirzaker C, Song JZ, Davidson B, Clark SJ. Transcriptional gene silencing promotes DNA hypermethylation through a sequential change in chromatin modifications in cancer cells. Cancer Res. 2004;64:3871-7.

70. Goldman R, Shields PG. Food mutagens. J Nutr. 2003;133 Suppl 3:965S-73S.

71. Matsuda T, Tao H, Goto M, Yamada H, Suzuki M, Wu Y, et al. Lipid peroxidation-induced DNA adducts in human gastric mucosa. Carcinogenesis. 2013;34:121-7.

72. Hemminki K. DNA adducts in biomonitoring. Toxicol Lett. 1995;77:227-9.

\section{Submit your next manuscript to BioMed Central and we will help you at every step:}

- We accept pre-submission inquiries

- Our selector tool helps you to find the most relevant journal

- We provide round the clock customer support

- Convenient online submission

- Thorough peer review

- Inclusion in PubMed and all major indexing services

- Maximum visibility for your research

Submit your manuscript at www.biomedcentral.com/submit
C Biomed Central 